\title{
Synthesis and Biological Activity of Reversed Pyrimidine Nucleosides
}

\author{
Nataša Župančić, ${ }^{a}$ Željka Ban, ${ }^{b}$ Josipa Matić, ${ }^{b}$ Dijana Saftić, \\ Ljubica Glavaš-Obrovac, ${ }^{c}$ and Biserka Žinićb,* \\ ${ }^{a}$ TAPI Research and Development, PLIVA Croatia Ltd., Prilaz baruna Filipovića 25, 10000 Zagreb, Croatia \\ ${ }^{\mathrm{b} D i v i s i o n}$ of Organic Chemistry and Biochemistry, Ruđer Bošković Institute, Bijenička cesta 54, 10000 Zagreb, Croatia \\ ${ }^{\mathrm{c}}$ Department of Clinical Chemistry, Biochemistry and Clinical Chemistry, Faculty of Medicine, J. J. Strossmayer \\ University of Osijek, Huttlerova 4,31000 Osijek, Croatia
}

RECEIVED SEPTEMBER 9, 2014; REVISED SEPTEMBER 22, 2014; ACCEPTED SEPTEMEBER 23, 2014

\begin{abstract}
An efficient approach to reversed nucleosides which enables their synthesis in gram quantities is described. $N$-1'-Pyrimidine reversed nucleosides were prepared by treating of the sodium salt of pyrimidine bases with protected 5-tosyl ribose. Additionally, $N-1$ ', $N$-3'-disubstituted reversed nucleosides were isolated in the condensation reactions with the 5-halogen pyrimidines. Using the Sonogashira coupling of 5 '-iodouracil reversed nucleoside with ethynyltrimethyl silane gave 5'-ethynyl derivative which was further transformed into 5'-acetyl reversed nucleoside. Biological activity of deprotected reversed nucleosides was validated on the panel of six human carcinoma cell lines (HeLa, MIAPaCa2, Hep2, NCI-H358, CaCo-2, and HT-29). 5'-Iodouracil derivative displayed moderate growth inhibition activity against human colon carcinoma $(\mathrm{CaCo}-2)$ cells.
\end{abstract}

Keywords: uracil, 5-halogenuracil, D-ribose, reversed nucleosides, antitumor activity

\section{INTRODUCTION}

Modified nucleosides represent a well known class of chemotherapeutic agents for treatment of viral ${ }^{1-4}$ and cancer $^{5,6}$ diseases. In the quest for new derivatives with a potent biological activity, many structural variations at the base and/or sugar moiety of natural nucleosides have been explored. ${ }^{7,8}$ The practical applicability of nucleoside analogues in chemotherapy largely depends on the stability of the drug in organism, because their catabolism usually includes degradation of nucleosidic linkage. Reversed or iso-nucleosides constitute a class of nucleoside analogues in which the nucleobase is linked to the sugar moiety through a carbon atom other than ribofuranose-C1. Hence, this class of compounds appears particularly interesting as drug candidates ${ }^{9-13}$ due to the lack of glycosidic linkage which makes them more stable to hydrolytic cleavage. In addition, the reversed nucleosides represent the largest pool of chiral synthons for the synthesis of aliphatic nucleoside analogues. ${ }^{14-20}$

In our previous communication we have reported on the synthesis of several partially and fully deprotected reversed and double headed nucleosides the former incorporating uracil or 5-iodouracil attached by $\mathrm{N1}^{\prime}$ at the C5 position of ribofuranose. ${ }^{19,21}$ In this work we present detailed experimental conditions for the synthesis of such reversed nucleosides and extend the synthesis to the highly interesting reversed nucleoside $\mathbf{1 3}$ incorporating 5-fluorouracil, the well-known anticancer drug. We also report on the preparation of the novel type of the nucleoside derivatives $\mathbf{9 , 1 1}$ and $\mathbf{1 5}$ containing the ribose fragments attached at both, the $\mathrm{N}^{\prime}$ and N3' positions of 5'-iodo and 5'-fluorouracil bases. The example of further synthetic modification of the reversed 5'-iodouracil nucleoside $\mathbf{1 0}$ into protected 5'ethinyl derivative 16 by the Sonogashira coupling reaction is also presented. Upon deprotection it becomes a versatile synthon for the click chemistry. The described synthetic studies enabling preparation of reversed nucleosides in the gram scale quantities are the prerequisite for biological testing and also open new perspectives for their synthetic transformations into novel optically active aliphatic or double headed nucleoside analogues, or sulfonamido and 1,2,3-triazolyl substituted reversed nucleoside derivatives. ${ }^{22}$ The prepared reversed nucleosides were tested for the antiproliferative activity on the panel of six human carcinoma cell lines (HeLa, MIAPaCa2, Hep2, NCI-H358, CaCo-2, and HT-29) and 5 '-iodouracil derivative $\mathbf{1 4}$ showed promising growth

\footnotetext{
* Author to whom correspondence should be addressed. (E-mail: bzinic@irb.hr)
} 
inhibition activity against human colon carcinoma $(\mathrm{Ca}-$ Co-2) cells.

\section{EXPERIMENTAL}

\section{General}

Solvents were distilled from appropriate drying agents shortly before use. TLC was carried out on DCplastikfolien Kieselgel $60 \mathrm{~F}_{254}$ and preparative thick layer $(2 \mathrm{~mm})$ chromatography was done on Merck 60 $\mathrm{F}_{254}$. Flash column chromatography was performed on silica gel Merck 0.040-0.063 mm. Melting points were determined on a Kofler hot-stage apparatus and were uncorrected. UV Spectra were taken on a Philips PU8700 UV/VIS spectrophotometer. IR spectra were obtained as $\mathrm{KBr}$ pellets on a Perkin-Elmer 297 spectrophotometer. ${ }^{1} \mathrm{H}$ and ${ }^{13} \mathrm{C}$ NMR spectra were recorded in DMSO- $d_{6}$ or $\mathrm{CDCl}_{3}$ on Varian Gemini $300(300 / 75$ $\mathrm{MHz}$ ) or Bruker AV 300 and $600 \mathrm{MHz}$ spectrometers using TMS or DMSO- $d_{6}$ as the internal standard. The order of C-atoms and protons were confirmed on the basis of 2D NMR HETCOR, COSY, and NOESY. Elemental analyses were done on a Perkin-Elmer 2400 Series II CHNS analyzer.

\section{The Following Compounds were Prepared according to Literature Procedures}

Methyl 2,3-O-isopropylidene- $\beta$-D-ribofuranoside (2) ${ }^{23,24}$ From D-ribose 1 (5.3 g, $32.84 \mathrm{mmol})$, compound 2 was obtained in $73 \%$ yield (4.99 g) as oil:

${ }^{1} \mathrm{H} \mathrm{NMR}\left(\mathrm{CDCl}_{3}\right) \delta / \mathrm{ppm}: 4.97$ (s, 1H, H-1), 4.82 (d, 1H, $J=6.0 \mathrm{~Hz}, \mathrm{H}-2), 4.59$ (d, 1H, $J=6.0 \mathrm{~Hz}, \mathrm{H}-3), 4.40$ (t, $1 \mathrm{H}, J=3.1 \mathrm{~Hz}, \mathrm{OH}), 3.64$ (m, 2H, H-4, H-5a), 3.46 (m, $\left.1 \mathrm{H}, \mathrm{H}-5_{\mathrm{b}}\right), 3.42\left(\mathrm{~s}, 3 \mathrm{H}, \mathrm{OCH}_{3}\right), 1.49$ (s, 3H, $\left.\mathrm{CCH}_{3}\right), 1.32$ $\left(\mathrm{s}, 3 \mathrm{H}, \mathrm{CCH}_{3}\right) ;{ }^{13} \mathrm{C} \mathrm{NMR}\left(\mathrm{CDCl}_{3}\right) \delta / \mathrm{ppm}: 112.03$ (s, O-C-O), 110.01 (s, C-1), 84.92 (d, C-4), 85.85 (d, C3), $82.00(\mathrm{~d}, \mathrm{C}-2), 64.02(\mathrm{t}, \mathrm{C}-5), 55.59\left(\mathrm{q}, \mathrm{OCH}_{3}\right)$, 26.50 (q, $\mathrm{CCH}_{3}$ ), 24.81 (q, $\mathrm{CCH}_{3}$ ).

Methyl 2,3-O-isopropylidene-5-O-p-toluenesulfonyl- $\beta$ D-ribofuranoside (3) ${ }^{23,24}$

From protected methyl ribofuranoside 2 (4.99 g, 24.43 $\mathrm{mmol}$ ) compound 3 was obtained in $76 \%$ yield $(6.7 \mathrm{~g})$ as a white crystals: $R_{\mathrm{f}}=0.3\left(\mathrm{CH}_{2} \mathrm{Cl}_{2} / \mathrm{MeOH} 20: 1\right)$; m.p. $=77-82{ }^{\circ} \mathrm{C} ;{ }^{1} \mathrm{H}$ NMR $\left(\mathrm{DMSO}-d_{6}\right) \delta / \mathrm{ppm}: 7.80(\mathrm{~d}, 2 \mathrm{H}, J$ $=8.3 \mathrm{~Hz}, \mathrm{Ph}), 7.50(\mathrm{~d}, 2 \mathrm{H}, J=8.0 \mathrm{~Hz}, \mathrm{Ph}), 4.91(\mathrm{~s}, 1 \mathrm{H}$, H-1), 4.62 (d, 1H, $J=5.9 \mathrm{~Hz}, \mathrm{H}-2), 4.50$ (d, 1H, $J=5.9$ $\mathrm{Hz}, \mathrm{H}-3), 4.20$ (t, 1H, $J=7.0 \mathrm{~Hz}, \mathrm{H}-4), 4.05$ (d, 2H, $J=$ $7.0 \mathrm{~Hz}, 2 \mathrm{H}-5), 3.10$ (s, 3H, OCH 3$), 2.42$ (s, 3H, $\underline{\mathrm{CH}}_{3}-$ $\mathrm{Ph}), 1.35\left(\mathrm{~s}, 3 \mathrm{H}, \mathrm{CCH}_{3}\right), 1.21\left(\mathrm{~s}, 3 \mathrm{H}, \mathrm{CCH}_{3}\right) ;{ }^{13} \mathrm{C} \mathrm{NMR}$ (DMSO- $\left.d_{6}\right) \delta / \mathrm{ppm}: 145.67(\mathrm{~s}, \mathrm{Ph}), 132.52$ (s, Ph), 130.71 (d, Ph), 128.16 (d, Ph), 112.20 (s, O-C-O), 109.25 (d, C-1), 84.61 (d, C-4), 83.61(d, C-2), 80.92 (d, C-3), 70.81 (t, C-5), 54.77 (q, $\left.\mathrm{OCH}_{3}\right), 26.61$ (q, $\mathrm{CCH}_{3}$ ),
25.04 (q, $\mathrm{CCH}_{3}$ ), 21.55 (q, $\mathrm{Ph}-\mathrm{CH}_{3}$ ).

\section{5-Iodopyrimidine-2,4(1H,3H)-dione $(6)^{25-27}$}

From uracil 4 (5 g, $0.045 \mathrm{~mol}$ ) compound 6 was obtained in $86 \%$ yield $(9.1 \mathrm{~g})$ as a white crystals: ${ }^{1} \mathrm{H}$ NMR (DMSO- $d_{6}$ ) $\delta /$ ppm: 11.43 (brs, 1H, NH-3), 11.14 (brs, $1 \mathrm{H}, \mathrm{NH}-1), 7,87$ (d, 1H, $J=5.9 \mathrm{~Hz}, \mathrm{H}-6) ;{ }^{13} \mathrm{C} \mathrm{NMR}$ (DMSO- $d_{6}$ ) $\delta / \mathrm{ppm}: 161.38$ (s, C-4), 151.16 (s, C-2), 146.92 (d, C-6), 67.41 (s, C-5).

\section{General Procedures for the Preparation of Reversed Nucleosides 7-11}

The sodium salt of base was prepared by stirring a suspension of an equimolar amount of the pyrimidine base 4-6 (1 mmol) and sodium hydride (50\% in oil suspension, $1 \mathrm{mmol})$ in DMF $(3-4 \mathrm{~mL} / \mathrm{mmol})$ at room temperature for $1 \mathrm{~h}$ and warming at $60-80{ }^{\circ} \mathrm{C}$ for $0.5 \mathrm{~h}$. A solution of the methyl 2,3-O-isopropylidene-5-O-ptoluenesulfonyl- $\beta$-D-ribofuranoside (3) $(0.8 \mathrm{mmol})$ in DMF $(1.7 \mathrm{~mL} / \mathrm{mmol}$ of sugar) was added dropwise to this suspension at room temperature. The reaction mixture was stirred and heated at $100{ }^{\circ} \mathrm{C}$ for 20 hours. The resulting clear solution was evaporated and the residue was dissolved in hot chloroform. The suspension was filtered through Celite and filtrate was washed with water, dried over $\mathrm{Na}_{2} \mathrm{SO}_{4}$ and evaporated.

Methyl 5-deoxy-5-(2,4-dioxopyrimidin-1H-1-yl)-2,3-Oisopropylidene- $\beta$-D-ribofuranoside (7)

Method A: Following the general procedure from uracil $4(1.8 \mathrm{~g}, 16 \mathrm{mmol})$ and after purification of the crude mixture by flash chromatography $\left(\mathrm{CH}_{2} \mathrm{Cl}_{2}: \mathrm{MeOH} 60: 1\right)$, compound 7 (1.42 g) was obtained in a yield of $37 \%$, as a white solid: $R_{\mathrm{f}}=0.26\left(\mathrm{CH}_{2} \mathrm{Cl}_{2} / \mathrm{MeOH} 20: 1\right)$; m.p. $187-188{ }^{\circ} \mathrm{C}$; UV (96 \% EtOH) $\lambda_{\max } / \mathrm{nm}: 207,228$ and 263, $\log \varepsilon / \mathrm{dm}^{3} \mathrm{~mol}^{-1} \mathrm{~cm}^{-1}: 3.96,3.39$ and 4.03; IR(KBr) $\tilde{v}_{\max } / \mathrm{cm}^{-1}: 3145(\mathrm{w}), 3090(\mathrm{~m}), 2995(\mathrm{~m}), 2925(\mathrm{~m})$, 1740 (s), 1705 (s), 1465 (s), 1420 (m), 1375 (m), 1245 (m), 1215 (m), 1090 (m), 1060 (m), 1025 (m), 955 (m); ${ }^{1} \mathrm{H}$ NMR $\left(\mathrm{CDCl}_{3}\right) \delta / \mathrm{ppm}$ : 9.38 (brs, $1 \mathrm{H}, \mathrm{NH}-3$ '), 7.25 (d, $\left.1 \mathrm{H}, J=7.9 \mathrm{~Hz}, \mathrm{H}-6^{\prime}\right), 5.71$ (dd, $1 \mathrm{H}, J=7.9 \mathrm{~Hz}, J=2.1$ Hz, H-5'), 5.00 (s, 1H, H-1), 4.65 (brs, 2H, H-2 and H3), 4.49 (dd, $1 \mathrm{H}, J=5.3, J=8.2 \mathrm{~Hz}, \mathrm{H}-4), 4.21$ (dd, $1 \mathrm{H}$, $J=5.3, J=13.8 \mathrm{~Hz}, \mathrm{H}-5 \mathrm{a}), 3.43$ (dd, $1 \mathrm{H}, J=8.2, J=$ $13.8 \mathrm{~Hz}, \mathrm{H}-5 \mathrm{~b}), 3.41\left(\mathrm{~s}, 3 \mathrm{H}, \mathrm{OCH}_{3}\right), 1.47$ (s, 3H, $\left.\mathrm{CCH}_{3}\right)$, $1.32\left(\mathrm{~s}, 3 \mathrm{H}, \mathrm{CCH}_{3}\right) ;{ }^{13} \mathrm{C}$ NMR $\left(\mathrm{CDCl}_{3}\right) \delta / \mathrm{ppm}: 163.71$ (s, C-4'), 150.90 (s, C-2'), 145.04 (d, C-6'), 112.92 (s, O-C-O), 110.61 (d, C-1), 102.03 (d, C-5'), 84.93 (d, C3), 84.37 (d, C-4), 81.83 (d, C-2), 55.93 (q, $\left.\mathrm{OCH}_{3}\right)$, 51.47 (t, C-5), 26.41 (q, $\mathrm{CCH}_{3}$ ), 25.00 (q, $\mathrm{CCH}_{3}$ ). Anal. Calcd. mass fractions of elements, $w / \%$, for $\mathrm{C}_{13} \mathrm{H}_{18} \mathrm{~N}_{2} \mathrm{O}_{6}$ $\left(M_{\mathrm{r}}=298.29\right)$ are: C 52.34, H 6.08, N 9.39; found: C 52.14, H 6.21, N 9.5.

Method B: Compound 10 (143 mg, $0.34 \mathrm{mmol})$ was dissolved in methanol $(50 \mathrm{~mL})$ and $0.1 \mathrm{M}$ aqueous $\mathrm{NaOH}(3.4 \mathrm{~mL})$ was added. The reaction mixture was 
cooled to $5{ }^{\circ} \mathrm{C}$ and purged with argon. Palladium on carbon catalyst $(79 \mathrm{mg}$ ) was added and the reaction mixture was treated with hydrogen gas (42 psi) in a Parr hydrogenation apparatus for $4 \mathrm{~h}$. The mixture was filtered through a Celite pad and washed with boiling methanol $(20 \mathrm{~mL})$. The combined methanol filtrates were concentrated under reduced pressure, dissolved in dichloromethane, washed with water, dried over $\mathrm{Na}_{2} \mathrm{SO}_{4}$ and evaporated. The product was crystallized from methanol to afford $82.6 \mathrm{mg}(82 \%)$ of 3 . The spectral properties were identical with a sample synthesized by method A.

Methyl 5-deoxy-5-(2,4-dioxo-5-fluoropyrimidin-1H-1yl)-2,3-O-isopropylidene- $\beta$-D-ribofuranoside (8) and 5fluoro-1,3-bis [(tetrahydro-4-methoxy-2,2-dimethylfuro [3,4-d][1,3]dioxol-6-yl)methyl]pyrimidine2,4(1H,3H)-dione (9)

Following the general procedure from 5-fluorouracil 5 (1.2 $\mathrm{g}, 9.2 \mathrm{mmol})$ and after purification of the crude mixture by flash chromatography $\left(\mathrm{CH}_{2} \mathrm{Cl}_{2} / \mathrm{MeOH} 60: 1\right)$, $N$-1'-regioisomer $8(537 \mathrm{mg})$ was obtained in a yield of $23 \%$ and $N-1^{\prime}, N-3^{\prime}$-disubstituted nucleoside 9 (931 mg) was obtained in a yield of $25 \%$, both in the form of foam:

$N$-1'-regioisomer 8: $R_{\mathrm{f}}=0.51 \quad\left(\mathrm{CH}_{2} \mathrm{Cl}_{2} / \mathrm{MeOH}\right.$ 20:1); UV (MeOH) $\lambda_{\max } 237$ and $288 \mathrm{~nm}, \log \varepsilon / \mathrm{dm}^{3}$ $\mathrm{mol}^{-1} \mathrm{~cm}^{-1}: 4.02$ and 4.11; IR(KBr) $\tilde{v}_{\max } / \mathrm{cm}^{-1}: 3450(\mathrm{w})$, 3220 (w), 3090 (w), 3080 (w), 2940 (w), 1741 (s), 1665 (s), 1385 (m), 1240 (m), 1215 (m), 1005 (m), 1090 (m); ${ }^{1} \mathrm{H}$ NMR (DMSO- $d_{6}$ ) $\delta / \mathrm{ppm}: 11.87(\mathrm{~s}, 1 \mathrm{H}, \mathrm{NH}-3$ '), 8.08 $\left(\mathrm{d}, 1 \mathrm{H}, J_{\mathrm{H}-\mathrm{F}}=6.9 \mathrm{~Hz}, \mathrm{H}-6\right.$ '), 4.95 (s, 1H, H-1), 4.74 (d, $1 \mathrm{H}, J=6.0 \mathrm{~Hz}, \mathrm{H}-2), 4.62$ (d, $1 \mathrm{H}, J=5.9 \mathrm{~Hz}, \mathrm{H}-3), 4.34$ (t, 1H, $J=7.2 \mathrm{~Hz}, \mathrm{H}-4), 3.86$ (dd, $1 \mathrm{H}, J=13.9, J=7.6$ Hz, H-5a), 3.59 (dd, 1H, $J=13.9, J=6.9 \mathrm{~Hz}, \mathrm{H}-5 \mathrm{~b}$ ), $3.28\left(\mathrm{~s}, 3 \mathrm{H}, \mathrm{OCH}_{3}\right), 1.37\left(\mathrm{~s}, 3 \mathrm{H}, \mathrm{CCH}_{3}\right), 1.25(\mathrm{~s}, 3 \mathrm{H}$, $\left.\mathrm{CCH}_{3}\right) ;{ }^{13} \mathrm{C}$ NMR (DMSO- $\left.d_{6}\right) \delta / \mathrm{ppm}: 157.71\left(\mathrm{~d}, J_{\mathrm{C}-\mathrm{F}}=\right.$ $26 \mathrm{~Hz}, \mathrm{C}-4$ ') 150.11 (s, C-2'), 139.85 (d, $J_{\mathrm{C}-\mathrm{F}}=230 \mathrm{~Hz}$, C-5'), 130.38 (d, $\left.J_{\mathrm{C}-\mathrm{F}}=34 \mathrm{~Hz}, \mathrm{C}-6^{\prime}\right), 111.94$ (s, O-C-O), 109.43 (d, C-1), 84.72 (d, C-3), 83.45 (d, C4), 81.32 (d, C-2), $54.99\left(\mathrm{q}, \mathrm{OCH}_{3}\right), 50.37$ (t, C-5), 26.31 (q, $\left.\mathrm{CCH}_{3}\right), 24.84$ (q, $\left.\mathrm{CCH}_{3}\right)$. Anal. Calcd. mass fractions of elements, $w / \%$, for $\mathrm{C}_{13} \mathrm{H}_{17} \mathrm{~N}_{2} \mathrm{O}_{6} \mathrm{~F}\left(M_{\mathrm{r}}=\right.$ 316.28) are: C 49.37, H 5.42, N 8.86; found: C 49.19, H 5.36, N 8.90.

$N-1^{\prime}, N-3^{\prime}$-disubstituted nucleoside 9: $R_{\mathrm{f}}=0.72$ $\left(\mathrm{CH}_{2} \mathrm{Cl}_{2} / \mathrm{MeOH} 20: 1\right)$; UV (MeOH) $\lambda_{\max } 238$ and 290 $\mathrm{nm}, \log \varepsilon / \mathrm{dm}^{3} \mathrm{~mol}^{-1} \mathrm{~cm}^{-1}: 3.92$ and 3.98; IR(KBr) $\tilde{v}_{\text {max }} / \mathrm{cm}^{-1}: 3090(\mathrm{w}), 3080(\mathrm{w}), 2940(\mathrm{w}), 1740(\mathrm{~s}), 1660$ (s), $1465(\mathrm{~m}), 1380(\mathrm{~m}), 1245$ (m), 1210 (m), 1166 (m), $1015(\mathrm{~m}), 1090(\mathrm{~m}) ;{ }^{1} \mathrm{H}$ NMR (DMSO-d $) \delta / \mathrm{ppm}: 8.19$ $\left(\mathrm{d}, 1 \mathrm{H}, J_{\mathrm{H}-\mathrm{F}}=6.5 \mathrm{~Hz}, \mathrm{H}-6\right.$ ) $), 4.95(\mathrm{~s}, 1 \mathrm{H}, \mathrm{H}-1), 4.93(\mathrm{~s}$, 1H, H-1"), 4.76 (d, 1H, J = 5.9 Hz, H-2), 4.69 (d, 1H, $J$ $=5.9 \mathrm{~Hz}, \mathrm{H}-2 "), 4.62$ (d, 1H, $J=5.9 \mathrm{~Hz}, \mathrm{H}-3), 4.60$ (d, $1 \mathrm{H}, J=5.9 \mathrm{~Hz}, \mathrm{H}-3 "), 4.38$ (t, $1 \mathrm{H}, J=7.2 \mathrm{~Hz}, \mathrm{H}-4)$, 4.24 (dd, $1 \mathrm{H}, J=9.0 \mathrm{~Hz}, J=4.9 \mathrm{~Hz}, \mathrm{H}-4 "), 4.80$ (dd,
$1 \mathrm{H}, J=13.2 \mathrm{~Hz}, J=9.2 \mathrm{~Hz}, \mathrm{H}-5 " \mathrm{a}), 4.01$ (dd, 1H, $J=$ $14.0 \mathrm{~Hz}, J=6.7 \mathrm{~Hz}, \mathrm{H}-5 \mathrm{a}), 3.90$ (dd, $1 \mathrm{H}, J=13.2,5.0$ Hz, H-5"b), 3.70 (dd, 1H, $J=14.0 \mathrm{~Hz}, J=7.6 \mathrm{~Hz}, \mathrm{H}-$ 5b), $3.30\left(\mathrm{~s}, 3 \mathrm{H}, \mathrm{OCH}_{3}\right), 3.28\left(\mathrm{~s}, 3 \mathrm{H}, \mathrm{OCH}_{3}\right), 1.37(\mathrm{~s}$, $\left.3 \mathrm{H}, \mathrm{CCH}_{3}\right), 1.34\left(\mathrm{~s}, 3 \mathrm{H}, \mathrm{CCH}_{3}\right), 1.25\left(\mathrm{~s}, 3 \mathrm{H}, \mathrm{CCH}_{3}\right)$, $1.22\left(\mathrm{~s}, 3 \mathrm{H}, \mathrm{CCH}_{3}\right) ;{ }^{13} \mathrm{C} \mathrm{NMR}\left(\mathrm{DMSO}-d_{6}\right) \delta / \mathrm{ppm}$ : 159.97 (s, C-4'), 150.99 (s, C-2'), 149.15 (d, C-6'), 128.26 (d, C-5'), 111.61 (s, O-C-O), 111.46 (s, O-C-O), 109.46 (d, C-1), 108.2 (d, C-1"), 84.60 (d, C-3 or C-3 "), 84.50 (d, C-3 or C-3"), 83.13 (C-4 and C-4"), 81.69 (C-2 or C-2"), 81.11 (C-2" or C-2), 55.06 (q, $\left.\mathrm{OCH}_{3}\right), 54.50\left(\mathrm{q}, \mathrm{OCH}_{3}\right), 51.52$ (t, C-5), 44.55 (t, C-5"), $26.24\left(\mathrm{q}, \mathrm{CCH}_{3}\right), 24.72\left(\mathrm{q}, \mathrm{CCH}_{3}\right)$. Anal. Calcd. mass fractions of elements, $w / \%$, for $\mathrm{C}_{22} \mathrm{H}_{31} \mathrm{~N}_{2} \mathrm{O}_{10} \mathrm{~F}\left(M_{\mathrm{r}}=\right.$ 502.49) are: C 52.59, H 6.22, N 5.57; found: C 52.65, H 6.30, N 5.58 .

Methyl 5-deoxy-5-(2,4-dioxo-5-iodopyrimidin-1H-1-yl)2,3-O-isopropylidene- $\beta$-D-ribofuranoside (10) and 5iodo-1,3-bis [(tetrahydro-4-methoxy-2,2-dimethylfuro[3,4-d][1,3]dioxol-6-yl)methyl]pyrimidine2,4(1H,3H)-dione (11)

Following the general procedure from 5-iodouracil 6 $(1.55 \mathrm{~g}, 6.5 \mathrm{mmol})$ and after purification of the crude mixture by flash chromatography $\left(\mathrm{CH}_{2} \mathrm{Cl}_{2} / \mathrm{MeOH} 60: 1\right)$, $N-1^{\prime}$-regioisomer 10 (1.27 g) was obtained in a yield of $58 \%$ as a white solid and $N-1^{\prime}, N-3^{\prime}$-disubstituted nucleoside 11 (47 mg) was obtained in a yield of $1.5 \%$ as a yellow foam.

$N$-1'-regioisomer 10: $R_{\mathrm{f}}=0.37\left(\mathrm{CH}_{2} \mathrm{Cl}_{2} / \mathrm{MeOH}\right.$ $20: 1)$; m.p. $182-183{ }^{\circ} \mathrm{C}$; UV(MeOH) $\lambda_{\max } / \mathrm{nm}: 215$ and 288, $\log \varepsilon / \mathrm{dm}^{3} \mathrm{~mol}^{-1} \mathrm{~cm}^{-1}: 4.13$ and 3.91; IR $(\mathrm{KBr})$ $\tilde{v}_{\max } / \mathrm{cm}^{-1}: 3190(\mathrm{~m}), 3100(\mathrm{~m}), 3050(\mathrm{~m}), 2995(\mathrm{~m})$, 1715 (s), 1655 (s), 1655 (s), 1450 (m), 1435 (m), 1400 (m), 1385 (m), 1360 (m), 1345 (m), 1240 (m), 1200 (m) $965(\mathrm{~m}) ;{ }^{1} \mathrm{H}$ NMR (DMSO- $\left.d_{6}\right) \delta / \mathrm{ppm}: 11.70$ (brs, $1 \mathrm{H}$, NH-3'), 8.10 (s, 1H, H-6'), 4.95 (s, 1H, H-1), 4.74 (d, $1 \mathrm{H}, J=5.8 \mathrm{~Hz}, \mathrm{H}-2), 4.62(\mathrm{~d}, 1 \mathrm{H}, J=5.8 \mathrm{~Hz}, \mathrm{H}-3)$, 4.35 (m, 1H, H-4), 3.94 (dd, $1 \mathrm{H}, J=6.7 \mathrm{~Hz}, J=13.8$ Hz, H-5a), 3.62 (dd, 1H, $J=7.6 \mathrm{~Hz}, J=13.8 \mathrm{~Hz}, \mathrm{H}-$ 5b), $3.31\left(\mathrm{~s}, 3 \mathrm{H}, \mathrm{OCH}_{3}\right), 1.37\left(\mathrm{~s}, 3 \mathrm{H}, \mathrm{CCH}_{3}\right), 1.26(\mathrm{~s}$, $\left.3 \mathrm{H}, \mathrm{CCH}_{3}\right) ;{ }^{13} \mathrm{C}$ NMR (DMSO- $\left.d_{6}\right) \delta / \mathrm{ppm}$ : 160.81 (s, C4'), 150.67 (s, C-2'), 150.15 (d, C-6'), 111.66 (s, O-CO), 109.37 (d, C-1), 84.51 (d, C-3), 83.24 (d, C-4), 81.05 (d, C-2), 68.08 (s, C-5'), $55.05\left(\mathrm{q}, \mathrm{OCH}_{3}\right), 50.41$ (t, C-5), 26.21 (q, $\left.\mathrm{CCH}_{3}\right), 24.72$ (q, $\left.\mathrm{CCH}_{3}\right)$. Anal. Calcd. mass fractions of elements, $w / \%$, for $\mathrm{C}_{13} \mathrm{H}_{17} \mathrm{~N}_{2} \mathrm{O}_{6} \mathrm{I}\left(M_{\mathrm{r}}=424.19\right)$ are: $\mathrm{C} 36.81, \mathrm{H} 4.04, \mathrm{~N}$ 6.61; found: C 36.65, H 3.96, N 6.78.

$N-1^{\prime}, N-3$ '-disubstituted nucleoside 11: $R_{\mathrm{f}}=0.62$ $\left(\mathrm{CH}_{2} \mathrm{Cl}_{2} / \mathrm{MeOH} 20: 1\right)$; UV(MeOH) $\lambda_{\max } / \mathrm{nm}: 217$ and $290\left(\log \varepsilon / \mathrm{dm}^{3} \mathrm{~mol}^{-1} \mathrm{~cm}^{-1}: 4.02\right.$ and 3.97); IR (KBr) $\tilde{v}_{\max } / \mathrm{cm}^{-1}: 2990(\mathrm{~m}), 2970(\mathrm{~m}), 1710$ (s), 1665 (br, s), 1630 (m), 1445 (br, m), 1385 (m), 1375 (m), 1340 (w), 1275 (m), 1240 (m), 1215 (m), 1160 (br, s), 870 (s); ${ }^{1} \mathrm{H}$ NMR (DMSO- $\left.d_{6}\right) \delta /$ ppm: 8.19 (s, 1H, H-6'), 4.95 (s, 
1H, H-1), 4.93 (s, 1H, H-1"), 4.76 (d, 1H, J=5.9 Hz, H2), 4.69 (d, 1H, $J=5,9 \mathrm{~Hz}, \mathrm{H}-2 "), 4.62$ (d, 1H, $J=5.9$ Hz, H-3), 4.60 (d, 1H, $J=5.9$ Hz, H-3"), 4.38 (pt, 1H, $J$ $=7.2 \mathrm{~Hz}, \mathrm{H}-4), 4.24$ (dd, $1 \mathrm{H}, J=9.0,4.9 \mathrm{~Hz}, \mathrm{H}-4 ")$, 4.08 (dd, 1H, $J=13.2,9.2 \mathrm{~Hz}, \mathrm{H}-5 " \mathrm{a}), 4.01$ (dd, 1H, $J=$ 14.0, 6.7 Hz, H-5a), 3.90 (dd, 1H, $J=13.2,5.0 \mathrm{~Hz}, \mathrm{H}-$ 5"b), 3.70 (dd, 1H, $J=14.0,7.6 \mathrm{~Hz}, \mathrm{H}-5 \mathrm{~b}), 3.30$ (s, 3H, $\left.\mathrm{OCH}_{3}\right), 3.28\left(\mathrm{~s}, 3 \mathrm{H}, \mathrm{OCH}_{3}\right), 1.37\left(\mathrm{~s}, 3 \mathrm{H}, \mathrm{OCH}_{3}\right), 1.34$ (s, 3H, $\left.\mathrm{OCH}_{3}\right), 1.25\left(\mathrm{~s}, 3 \mathrm{H}, \mathrm{OCH}_{3}\right), 1.22\left(\mathrm{~s}, 3 \mathrm{H}, \mathrm{OCH}_{3}\right)$; ${ }^{13} \mathrm{C}$ NMR (DMSO- $\left.d_{6}\right) \delta / \mathrm{ppm}: 159.97$ (s, C-4'), 150.99 (s, C-2'), 149.08 (d, C-6'), $111.62(\mathrm{~s}, \mathrm{O}-\mathrm{C}-\mathrm{O}), 111.46$ (s, O-C-O), 109.46 (d, C-1), 108.72 (d, C-1"), 84.60 (d, C-3), 84.50 (d, C-3"), 83.13 (brd, C-4, C-4"), 81.69 (d, C-2), 81.11 (d, C-2"), 67.11 (s, C-5'), 55.07 (q, $\mathrm{OCH}_{3}$ ), $54.51\left(\mathrm{q}, \mathrm{OCH}_{3}\right), 51.52(\mathrm{t}, \mathrm{C}-5), 44.55$ (t, C-5"), 26.24 $\left(\mathrm{q}, \mathrm{CCH}_{3}\right), 26.20\left(\mathrm{q}, \mathrm{CCH}_{3}\right), 24.72\left(\mathrm{q}, \mathrm{CCH}_{3}\right)$. Anal. Calcd. mass fractions of elements, $w / \%$, for $\mathrm{C}_{22} \mathrm{H}_{31} \mathrm{~N}_{2} \mathrm{O}_{10} \mathrm{I}\left(M_{\mathrm{r}}=610.39\right)$ are: $\mathrm{C} 43.29, \mathrm{H} 5.12, \mathrm{~N}$ 4.59; found: C 43.15, H 5.07, N 4.70.

General Procedure for the Hydrolysis of Isopropylidene Protecting Group of Reversed Nucleosides 7-10 and 17

To a solution of reversed nucleoside $(1 \mathrm{mmol})$ in methanol (11-15 $\mathrm{mL} / \mathrm{mmol})$ Amberlite IR-120 $\left(\mathrm{H}^{+}\right)$ion exchange resin $(3.3 \mathrm{~g} / \mathrm{mmol})$, that has been washed several times with absolute methanol, was added. The mixture was refluxed for $8 \mathrm{~h}$, cooled and filtered through a Celite pad, and the resin was washed with methanol $(\approx 20 \mathrm{~mL})$. The filtrate and washings were combined and evaporated.

Methyl 5-deoxy-5-(2,4-dioxopyrimidin-1H-1-yl)- $\beta$ - $D$ ribofuranoside (12)

Following the general procedure from reversed nucleoside $7(80 \mathrm{mg}, 0.27 \mathrm{mmol})$ the resulting mixture was purified by preparative TLC with $\mathrm{CH}_{2} \mathrm{Cl}_{2} / \mathrm{MeOH}$ (9:1) as eluents. The major band was eluted, evaporated to afford $62 \mathrm{mg}(89 \%)$ of $\mathbf{1 2}$ as a foam: $R_{\mathrm{f}}=0.32$ $\left(\mathrm{CH}_{2} \mathrm{Cl}_{2} / \mathrm{MeOH}\right.$ 9:1); UV(MeOH) $\lambda_{\max } / \mathrm{nm}: 208$ and 265, $\log \varepsilon / \mathrm{dm}^{3} \mathrm{~mol}^{-1} \mathrm{~cm}^{-1}: 3.72$ and 3.80; IR (KBr) $\tilde{v}_{\max } / \mathrm{cm}^{-1}: 3420(\mathrm{~s}), 2940(\mathrm{~m}), 1685$ (s), $1530(\mathrm{~m}), 1385$ (m), 1350 (m), 1255 (m) 1130 (m), 1085 (m), 1025 (m); ${ }^{1} \mathrm{H}$ NMR (DMSO- $d_{6}$ ) $\delta /$ ppm: (anomers $\beta: \alpha$ 10:1) $\beta$ anomer: 11.40 (brs, $\left.1 \mathrm{H}, \mathrm{NH}-3^{\prime}\right), 7.50$ (d, $1 \mathrm{H}, J=7.9 \mathrm{~Hz}$, H-6'), 5.54 (d, 1H, J=7.9 Hz, H-5'), 5.08 (brs, 2H, OH2 and OH-3), 4.83 (s, 1H, H-1), 4.01-3.62 (m, 5H, H-2, $\mathrm{H}-3, \mathrm{H}-4$ and $2 \mathrm{H}-5), 3.40\left(\mathrm{~s}, 3 \mathrm{H}, \mathrm{OCH}_{3}\right) ;{ }^{13} \mathrm{C} \mathrm{NMR}$ (DMSO- $\left.d_{6}\right) \delta /$ ppm: ( $\beta$-anomer) 163.94 (s, C-4'), 151.18 (s, C-2'), 146.62 (d, C-6'), 108.58 (d, C-1), 100.62 (d, C5') 79.63 (d, C-4), 74.38 (d, C-2), 72.46 (d, C-3), 54.97 $\left(\mathrm{q}, \mathrm{OCH}_{3}\right), 50.74(\mathrm{t}, \mathrm{C}-5)$. Anal. Calcd. mass fractions of elements, $w / \%$, for $\mathrm{C}_{10} \mathrm{H}_{14} \mathrm{~N}_{2} \mathrm{O}_{6}\left(M_{\mathrm{r}}=258.23\right)$ are: $\mathrm{C}$ 46.51, H 5.46, N 10.85; found: C 46.31, H 5.69, N 10.73 .
Methyl 5-deoxy-5-(2,4-dioxo-5-fluoropyrimidin-1H-1$y$ l)- $\beta$-D-ribofuranoside (13)

Following the general procedure from reversed nucleoside $8(250 \mathrm{mg}, 0.79 \mathrm{mmol})$ the product 13 was obtained in $79 \%(72 \mathrm{mg})$ yield as a foam: $R_{\mathrm{f}}=0.21$ $\left(\mathrm{CH}_{2} \mathrm{Cl}_{2} / \mathrm{MeOH} 9: 1\right)$; UV (MeOH) $\lambda_{\max } / \mathrm{nm}$ : 235 and 288, $\log \varepsilon / \mathrm{dm}^{3} \mathrm{~mol}^{-1} \mathrm{~cm}^{-1}: 3.90$ and 4.10; IR(KBr) $\tilde{v}_{\max } / \mathrm{cm}^{-1}$ : $3445(\mathrm{~m}), 3210(\mathrm{~m}), 3080(\mathrm{w}), 2945(\mathrm{w})$, 1745 (s), 1665 (s), 1475 (w), 1380 (m), 1230 (m), 1210 (m), $1150(\mathrm{w}), 1130$ (m), 1045 (m), 1035 (w); ${ }^{1} \mathrm{H}$ NMR (DMSO- $\left.d_{6}\right) \delta /$ ppm: $\beta$-anomer: $7.91\left(\mathrm{~d}, 1 \mathrm{H}, J_{\mathrm{H}-\mathrm{F}}=6.8\right.$ Hz, H-6'), 5.34-5.01 (brs, 1H, OH-2), 4.64 (s, 1H, H$\left.1_{\beta}\right)$, 4.12-3.57 (m, 6H, OH-3, H-2, H-3, H-4, 2H-5), $3.25\left(\mathrm{~s}, 3 \mathrm{H}, \mathrm{OCH}_{3}\right) .{ }^{13} \mathrm{C} \mathrm{NMR}\left(\mathrm{DMSO}-d_{6}\right) \delta / \mathrm{ppm}: \beta-$ anomer: 157.94 (d, ${ }^{3} J_{\mathrm{C}-\mathrm{F}}=23 \mathrm{~Hz}, \mathrm{C}-4$ '), 150.11 (s, C-2'), $139.31\left(\mathrm{~d}, J_{\mathrm{C}-\mathrm{F}}=227 \mathrm{~Hz}, \mathrm{C}-5{ }^{\prime}\right), 130.68\left(\mathrm{~d},{ }^{3} J_{\mathrm{C}-\mathrm{F}}=34 \mathrm{~Hz}\right.$, C-6'), 108.45 (d, C-1), 79.36 (d, C-4), 74.26 (d, C-2), 72.28 (d, C-3), 54.79 (q, $\left.\mathrm{OCH}_{3}\right), 50.42$ (t, C-5); $\alpha-$ anomer: ${ }^{13} \mathrm{C}$ NMR (DMSO- $\left.d_{6}\right) \delta /$ ppm: $157.94\left(\mathrm{~d},{ }^{3} J_{\mathrm{C}-\mathrm{F}}=\right.$ $23 \mathrm{~Hz}, \mathrm{C}-4$ '), 150.11 (s, C-2'), 139.31 (d, $J_{\mathrm{C}-\mathrm{F}}=227 \mathrm{~Hz}$, C-5'), 130.68 (d, ${ }^{3} J_{\mathrm{C}-\mathrm{F}}=34 \mathrm{~Hz}, \mathrm{C}-6$ '), 102.83 (d, C-1), 81.00 (d, C-4), 70.99 (d, C-3 or C-2), 70.04 (d, C-3 or $\mathrm{C}-2), 54.83$ (q, $\left.\mathrm{OCH}_{3}\right), 50.42$ (t, C-5). Anal. Calcd. mass fractions of elements, $w / \%$, for $\mathrm{C}_{10} \mathrm{H}_{13} \mathrm{~N}_{2} \mathrm{O}_{6} \mathrm{~F}\left(M_{\mathrm{r}}=\right.$ 276.22) are: C 43.48, H 4.74, N 10.14; found: C 43.51, H 4.70, N 10.19.

Methyl 5-deoxy-5-(2,4-dioxo-5-iodopyrimidin-1H-1-yl)$\beta$-D-ribofuranoside (14)

Following the general procedure from reversed nucleoside 10 (498 mg, $1.15 \mathrm{mmol})$ the product was crystallized from methanol to afford $381 \mathrm{mg}(89 \%)$ of 14 as a white crystals: $R_{\mathrm{f}}=0.48\left(\mathrm{CH}_{2} \mathrm{Cl}_{2} / \mathrm{MeOH} 9: 1\right) ;$ m.p. 99-101 ${ }^{\circ} \mathrm{C}$; $\mathrm{UV}(\mathrm{MeOH}) \lambda_{\max } / \mathrm{nm}: 213$ and 287, log $\varepsilon / \mathrm{dm}^{3} \mathrm{~mol}^{-1} \mathrm{~cm}^{-1}: 4.14$ and 3.98; IR (KBr) $\tilde{v}_{\max } / \mathrm{cm}^{-1}$ : 3430 (m), 3050 (w), 2970 (w), 1730 (s), 1715 (s), 1665 (s), $1610(\mathrm{~m}), 1445(\mathrm{w}), 1420(\mathrm{w}), 1340(\mathrm{w}), 1300(\mathrm{w})$, 1255 (m), 1125 (m), 1100 (w), $1080(\mathrm{w}), 1025$ (m); ${ }^{1} \mathrm{H}$ NMR (DMSO- $d_{6}$ ) $\delta /$ ppm: (anomers $\left.\beta: \alpha 10: 1\right) \beta$-anomer: 11.65 (brs, 1H, NH-3'), 8.02 (s, 1H, H-6'), 5.13 (d, 1H, J $=4.1 \mathrm{~Hz}, \mathrm{OH}-2), 4.99(\mathrm{~d}, 1 \mathrm{H}, J=5.3 \mathrm{~Hz}, \mathrm{OH}-3), 4.64$ (s, 1H, H-1), 4.06-3.68 (m, 5H, H-2, H-3, H-4 and 2H5), $3.25\left(\mathrm{~s}, 3 \mathrm{H}, \mathrm{CH}_{3} \mathrm{O}\right) ;{ }^{13} \mathrm{C}$ NMR (DMSO- $\left.d_{6}\right) \delta / \mathrm{ppm}$ : $\left(\beta\right.$-anomer) $161.06\left(\mathrm{~s}, \mathrm{C}-4^{\prime}\right), 150.85$ (s, C-2'), 150.85 (d, C-6'), 108.64 (d, C-1), 79.69 (d, C-4), 74.44 (d, C-2), 72.18 (d, C-3), 67.50 (s, C-5'), 55.14 (q, $\mathrm{CH}_{3} \mathrm{O}$ ), 50.17 (t, C-5). Anal. Calcd. mass fractions of elements, $w / \%$, for $\mathrm{C}_{10} \mathrm{H}_{13} \mathrm{~N}_{2} \mathrm{O}_{6} \mathrm{I}\left(M_{\mathrm{r}}=384.12\right)$ are: $\mathrm{C} 31.27, \mathrm{H} 3.41, \mathrm{~N}$ 7.29; found: C 31.41, H 3.68, N 7.37.

5-Fluoro-1,3-bis [(tetrahydro-3,4-dihydroxy-5-methoxyfuran-2-yl)methyl Jpyrimidine-2,4(1H,3H)-dione (15)

Following the general procedure from reversed nucleoside 9 (385 mg, $0.77 \mathrm{mmol})$ the product 15 was obtained in $65 \%(210 \mathrm{mg})$ yield as a foam: $R_{\mathrm{f}}=0.35$ $\left(\mathrm{CH}_{2} \mathrm{Cl}_{2} / \mathrm{MeOH}\right.$ 9:1); UV (MeOH) $\lambda_{\max } / \mathrm{nm}: 237$ and 
291, $\log \varepsilon / \mathrm{dm}^{3} \mathrm{~mol}^{-1} \mathrm{~cm}^{-1}: 3.91$ and 4.10; IR(KBr) $\tilde{v}_{\max } / \mathrm{cm}^{-1}$ : $3440(\mathrm{~m}), 3215(\mathrm{~m}), 3000(\mathrm{w}), 2945(\mathrm{w})$, 1740 (s), 1655 (s), 1455 (w), 1370 (m), 1230 (m), 1210 (m), $1135(\mathrm{~m}), 1040(\mathrm{~m}), 1030(\mathrm{w}), 955(\mathrm{w}) ;{ }^{1} \mathrm{H}$ NMR (DMSO- $d_{6}$ ) $\delta / \mathrm{ppm}$ : (anomers $\beta: \alpha$ 10:3) $\beta$-anomer: 8.07 $\left(\mathrm{d}, 1 \mathrm{H}, J=6.4 \mathrm{~Hz}, \mathrm{H}-6^{\prime} \alpha\right), 8.03$ (d, $1 \mathrm{H}, J=6.5 \mathrm{~Hz}, \mathrm{H}-$ 6ß), 5.08 (brs, 4H, OH), 4.64 (s, 1H, H-1), 4.59 (s, 1H, H-1"), 4.14-3,29 (m, 10H, H-2, H-3, H-4, 2H-5, H-2", H-3", H-4", 2H-5"), 3.26 (s, 3H, $\left.\mathrm{OCH}_{3}\right), 3.23$ (s, 3H, $\left.\mathrm{OCH}_{3}\right) ;{ }^{13} \mathrm{C}$ NMR (DMSO- $\left.d_{6}\right) \quad \delta / \mathrm{ppm}:(\beta$-anomer) $156.84\left(\mathrm{~d},{ }^{3} J_{\mathrm{C}-\mathrm{F}}=15 \mathrm{~Hz}, \mathrm{C}-4^{\prime}\right), 149.66$ (s, C-2'), 140.14, $138.64\left(\mathrm{~d}, J_{\mathrm{C}-\mathrm{F}}=226 \mathrm{~Hz}, \mathrm{C}-5^{\prime}\right), 129.64\left(\mathrm{~d}, J_{\mathrm{C}-\mathrm{F}}=33 \mathrm{~Hz}\right.$, C-6'), 108.50 (d, C-1), 108.20 (d, C-1"), 79.22 (d, C-4), 78.18 (d, C-4"), 74.50 (d, C-2 or 2"), 74.28 (d, C-2 or 2"), 73.40 (d, C-3 or C-3"), 72.32 (d, C-3 or C-3"), 54.84 $\left(\mathrm{q}, \mathrm{OCH}_{3}\right), 54.39\left(\mathrm{q}, \mathrm{OCH}_{3}\right), 51.74(\mathrm{t}, \mathrm{C}-5), 44.70(\mathrm{t}, \mathrm{C}-$ $5 ")$. Anal. Calcd. mass fractions of elements, $w / \%$, for $\mathrm{C}_{16} \mathrm{H}_{23} \mathrm{~N}_{2} \mathrm{O}_{10} \mathrm{~F}\left(M_{\mathrm{r}}=422.36\right)$ are: $\mathrm{C} 45.50, \mathrm{H} 5.49, \mathrm{~N}$ 6.63; found: C 45.42, H 5.41, N 6.72.

Methyl 5-deoxy-5-\{2,4-dioxo-5-[(2-trimethylsilyl)ethynyl]pyrimidin-1H-1-yl \}-2,3-O-isopropylidene- $\beta$ - $D$ ribofuranoside (16)

A suspension of $\mathbf{1 0}$ (200 $\mathrm{mg}, \quad 0.47 \quad \mathrm{mmol})$, bis(triphenylphosphine)palladium(II) chloride $(33 \mathrm{mg}$, $0.047 \mathrm{mmol})$ and cooper(I) iodide $(0.9 \mathrm{mg}, 0.0047$ $\mathrm{mmol})$ in a degassed triethylamine $(19 \mathrm{~mL})$ was stirred vigorously and purged with argon. Excess ethynyltrimethylsilane (55 mg, $0.56 \mathrm{mmol}$ ) was added and the reaction mixture was stirred under argon in an oil bath at $50{ }^{\circ} \mathrm{C}$ for $8 \mathrm{~h}$. The reaction mixture was cooled and evaporated. The colored residue was dissolved in chloroform $(50 \mathrm{~mL})$, washed with $5 \%$ disodium EDTA $/ \mathrm{H}_{2} \mathrm{O}(2 \times 20 \mathrm{~mL})$ and water $(20 \mathrm{~mL})$, dried over $\mathrm{Na}_{2} \mathrm{SO}_{4}$ and evaporated. The resulting mixture was purified by flash column chromatography on silica gel. The product was eluted with $\mathrm{CH}_{2} \mathrm{Cl}_{2} / \mathrm{MeOH}(20: 1)$ and (9:1), evaporated and crystallized from chloroform to afford $132 \mathrm{mg}(71 \%)$ of $\mathbf{1 6}$ as a white crystals: $R_{\mathrm{f}}=$ $0.39\left(\mathrm{CH}_{2} \mathrm{Cl}_{2} / \mathrm{MeOH} 20: 1\right)$; m.p. $207-208{ }^{\circ} \mathrm{C}$; UV $(\mathrm{MeOH}) \lambda_{\max } / \mathrm{nm}: 233$ and 296, log $\varepsilon / \mathrm{dm}^{3} \mathrm{~mol}^{-1} \mathrm{~cm}^{-1}$ : 4.12 and 4.19; IR(KBr) $\tilde{v}_{\max } / \mathrm{cm}^{-1}: 3195(\mathrm{~m}), 3095(\mathrm{~m})$, $2990(\mathrm{w}), 2950(\mathrm{~m}), 2160(\mathrm{w}), 1745(\mathrm{~m}), 1715(\mathrm{~s})$, $1695(\mathrm{~s}), 1625(\mathrm{~m}), 1450(\mathrm{~m}), 1385(\mathrm{~m}), 1375(\mathrm{~m})$, $1355(\mathrm{~m}), 1245(\mathrm{~m}), 1230(\mathrm{~s}), 1210(\mathrm{~m}), 1160(\mathrm{~m})$, 1105 (m), 1080 (s), 1060 (m), 1040 (m); ${ }^{1} \mathrm{H}$ NMR $\left(\mathrm{CDCl}_{3}\right) \delta$ /ppm: 9.85 (brs, 1H, NH-3'), 7.54 (s, 1H, H6'), 5.02 (s, 1H, H-1), 4.68 (brs, 2H, H-2 and H-3), $4.51\left(\mathrm{dd}, 1 \mathrm{H}, J_{4,5 \mathrm{a}}=5.6, J_{4,5 \mathrm{~b}}=8.5 \mathrm{~Hz}, \mathrm{H}-4\right), 4.21(\mathrm{dd}$, $\left.1 \mathrm{H}, J_{5 \mathrm{a}, 4}=5.6, J_{\mathrm{a}, \mathrm{b}}=14.1 \mathrm{~Hz}, \mathrm{H}-5 \mathrm{a}\right), 3.49\left(\mathrm{dd}, 1 \mathrm{H}, J_{5 \mathrm{~b}, 4}\right.$ $\left.=8.5, J_{\mathrm{b}, \mathrm{a}}=14.1 \mathrm{~Hz}, \mathrm{H}-5 \mathrm{~b}\right), 3.44\left(\mathrm{~s}, 3 \mathrm{H}, \mathrm{CH}_{3} \mathrm{O}\right), 1.47$ $\left(\mathrm{s}, 3 \mathrm{H}, \mathrm{CH}_{3} \mathrm{C}\right), 1.33\left(\mathrm{~s}, 3 \mathrm{H}, \mathrm{CH}_{3} \mathrm{C}\right), 0.21(\mathrm{~s}, 9 \mathrm{H}$, $\left.\left(\mathrm{CH}_{3}\right)_{3} \mathrm{Si}\right) ;{ }^{13} \mathrm{C}$ NMR $\left(\mathrm{CDCl}_{3}\right) \delta / \mathrm{ppm}: 161.57$ (s, C-4'), 149.67 (s, C-2'), 148.47 (d, C-6'), 112.76 (s, O-C-O),

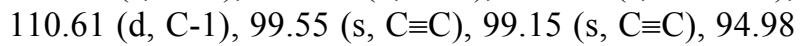
(s, C-5'), 84.82 (d, C-3), 83.69 (d, C-4), 81.49 (d, C-2),
55.93 (q, $\left.\mathrm{CH}_{3} \mathrm{O}\right), 51.47$ (t, C-5), 26.19 (q, $\mathrm{CH}_{3} \mathrm{C}$ ), 24.77 (q, $\left.\mathrm{CH}_{3} \mathrm{C}\right), 0.00\left(\left(\mathrm{CH}_{3}\right)_{3} \mathrm{Si}\right)$. Anal. Calcd. mass fractions of elements, $w / \%$, for $\mathrm{C}_{18} \mathrm{H}_{26} \mathrm{~N}_{2} \mathrm{O}_{6} \mathrm{Si}\left(M_{\mathrm{r}}=\right.$ 394.50) are: C 54.80, H 6.64, N 7.10; found: C 54.58, H 6.61, N 7.07.

Methyl 5-deoxy-5-(2,4-dioxo-5-acetylpyrimidin-1H-1$y l)$ - $\beta$-D-ribofuranoside (17)

Method A: Following the general procedure for the hydrolysis of isopropylidene protecting group: from reversed nucleoside 16 (369 $\mathrm{mg}, 0.94 \mathrm{mmol})$ the product was crystallized from methanol to afford $217 \mathrm{mg}$ $(78 \%)$ of $\mathbf{1 7}$ as white crystals: $R_{\mathrm{f}}=0.42$ $\left(\mathrm{CH}_{2} \mathrm{Cl}_{2} / \mathrm{MeOH} 9: 1\right)$; m.p. $189-190{ }^{\circ} \mathrm{C}$; $\mathrm{UV}(\mathrm{MeOH})$ $\lambda_{\max } / \mathrm{nm}: 228$ and $290, \log \varepsilon / \mathrm{dm}^{3} \mathrm{~mol}^{-1} \mathrm{~cm}^{-1}: 3.99$ and 4.06; IR(KBr) $\tilde{v}_{\max } / \mathrm{cm}^{-1}: 3440(\mathrm{w}), 3000(\mathrm{w}), 1730(\mathrm{~s})$, 1710 (s), 1685 (s), 1675 (s), 1605 (m), 1470 (m), 1430 $(\mathrm{w}), 1385(\mathrm{~m}), 1365(\mathrm{~m}), 1330(\mathrm{~m}), 1250(\mathrm{w}) ;{ }^{1} \mathrm{H}$ NMR (DMSO- $\left.d_{6}\right) \delta /$ ppm: $\beta$-anomer: 11.65 (brs, $1 \mathrm{H}$, NH-3'), 8.31 (s, 1H, H-6'), $5.16(\mathrm{~d}, 1 \mathrm{H}, J=4.3 \mathrm{~Hz}$, $\mathrm{OH}), 5.05$ (d, 1H, $J=6.5 \mathrm{~Hz}, \mathrm{OH}), 4.63$ (s, 1H, H-1), $4.16(\mathrm{dd}, 1 \mathrm{H}, J=13.7 \mathrm{~Hz}, J=3.4 \mathrm{~Hz}, \mathrm{H}-5 \mathrm{a})$, 4.04-3.91 (m, 1H, H-5b), 3.91-3.77 (m, 2H, H-4, H3), $3.74(\mathrm{t}, 1 \mathrm{H}, J=4.1 \mathrm{~Hz}, \mathrm{H}-2), 3.22\left(\mathrm{~s}, 3 \mathrm{H}, \mathrm{OCH}_{3}\right)$, $2.46\left(\mathrm{~s}, 3 \mathrm{H}, \mathrm{COCH}_{3}\right) ;{ }^{13} \mathrm{C}$ NMR (DMSO- $\left.d_{6}\right) \delta / \mathrm{ppm}: \beta$ anomer: $194.40\left(\mathrm{~s}, \mathrm{COCH}_{3}\right), 162.14(\mathrm{~s}, \mathrm{C}-4$ '), 153.20 (d, C-6'), 150.23 (s, C-2'), 111.45 (s, C-5'), 109.09 (d, C-1), 79.80 (d, C-4), 74.22 (d, C-2), 72.35 (d, C-3), 55.53 (q, $\left.\mathrm{CH}_{3} \mathrm{O}\right), 51.30$ (t, C-5), 30.54 (q, $\mathrm{CH}_{3} \mathrm{CO}$ ). Anal. Calcd. mass fractions of elements, $w / \%$, for $\mathrm{C}_{12} \mathrm{H}_{16} \mathrm{~N}_{2} \mathrm{O}_{7}\left(M_{\mathrm{r}}=300.27\right)$ are: $\mathrm{C} 48.00, \mathrm{H} 5.37, \mathrm{~N}$ 9.33; found: C 47.93, H 5.40, N 9.40.

Method B: Reversed nucleoside 16 (400 mg, 1.01 mmol) was stirred at room temperature for $4 \mathrm{~h}$ in a $2: 1$ mixture of TFA $/ \mathrm{H}_{2} \mathrm{O}(20 \mathrm{~mL})$. After evaporation of volatiles, the crude residue was purified by flash chromatography $\left(\mathrm{CH}_{2} \mathrm{Cl}_{2} / \mathrm{MeOH} 9: 1\right)$. The product was crystallized from methanol to afford $237 \mathrm{mg}$ (78 $\%)$ of $\mathbf{1 7}$ as white crystals. The spectral properties were identical with a sample synthesized by method A. Method C: Reversed nucleoside 18 (350 mg, 1.09 mmol) was stirred at room temperature for $3 \mathrm{~h}$ in a $2: 1$ mixture of $\mathrm{TFA} / \mathrm{H}_{2} \mathrm{O}(20 \mathrm{~mL})$. After evaporation of volatiles, the crude residue was purified by flash chromatography $\left(\mathrm{CH}_{2} \mathrm{Cl}_{2} / \mathrm{MeOH}\right.$ 9:1). The product was crystallized from methanol to afford $317 \mathrm{mg}$ (97\%) of 17 as white crystals. The spectral properties were identical with a sample synthesized by method A.

Methyl 5-deoxy-5-(2,4-dioxo-5-ethynylpyrimidin-1H-1yl)-2,3-O-isopropylidene- $\beta$-D-ribofuranoside (18)

A solution of (trimethylsilyl)ethynyl derivative $\mathbf{1 6}$ (107 mg, $0.27 \mathrm{mmol}$ ) in $0.2 \mathrm{M}$ solution of sodium methoxide in methanol $(5.5 \mathrm{ml})$ was stirred $30 \mathrm{~min}$ at room temperature. The solution was carefully neutralized by addition of Amberlite IR-120 $\left(\mathrm{H}^{+}\right)$ion ex- 
change resin until moistened $\mathrm{pH}$ paper indicated $\mathrm{pH} \approx$ 6 . The mixture was filtered and the resin was washed with methanol. The combined filtrate was evaporated and the product was crystallized from $\mathrm{CH}_{2} \mathrm{Cl}_{2} /$ hexane to afford $72 \mathrm{mg}(88 \%)$ of $\mathbf{1 8}$ as white crystals: $R_{\mathrm{f}}=$ 0.43 (diethyl ether); m.p. $211-212{ }^{\circ} \mathrm{C}$; UV (MeOH) $\lambda_{\text {max }} / \mathrm{nm}: 227$ and 290, $\log \varepsilon / \mathrm{dm}^{3} \mathrm{~mol}^{-1} \mathrm{~cm}^{-1}: 3.80$ and 3.87; IR(KBr) $\tilde{v}_{\max } / \mathrm{cm}^{-1}: 3270(\mathrm{~m}), 3200(\mathrm{w}), 2100$ (vw), 1710 (s), 1680 (s), 1630 (s), 1460 (s), 1435 (m), $1405(\mathrm{w}), 1385(\mathrm{~m}), 1375(\mathrm{~m}), 1370(\mathrm{~m}), 1240(\mathrm{~m})$, $1205(\mathrm{~m}) \mathrm{cm}^{-1}$; ${ }^{1} \mathrm{H}$ NMR $\left(\mathrm{CDCl}_{3}\right) \delta / \mathrm{ppm}: 8.75$ (brs, 1H, NH-3'), 7.57 (s, 1H, H-6'), 5.01 (s, 1H, H-1), 4.66 (brs, $2 \mathrm{H}, \mathrm{H}-2$ and $\mathrm{H}-3), 4.50\left(\mathrm{dd}, 1 \mathrm{H}, J_{4,5 \mathrm{a}}=5.1 \mathrm{~Hz}\right.$, $\left.J_{4,5 \mathrm{~b}}=8.7 \mathrm{~Hz}, \mathrm{H}-4\right), 4.22\left(\mathrm{dd}, 1 \mathrm{H}, J_{5 \mathrm{a}, 4}=5.1 \mathrm{~Hz}, J_{\mathrm{a}, \mathrm{b}}=\right.$ $14.1 \mathrm{~Hz}, \mathrm{H}-5 \mathrm{a}), 3.49$ (dd, $1 \mathrm{H}, J_{5 \mathrm{~b}, 4}=8.7 \mathrm{~Hz}, J_{\mathrm{b}, \mathrm{a}}=14.1$ $\mathrm{Hz}, \mathrm{H}-5 \mathrm{~b}), 3.44$ (s, 3H, $\left.\mathrm{CH}_{3} \mathrm{O}\right), 3.17$ (s, 1H, C $\left.\equiv \mathrm{CH}\right)$, $1.47\left(\mathrm{~s}, 3 \mathrm{H}, \mathrm{CH}_{3} \mathrm{C}\right), 1.33\left(\mathrm{~s}, 3 \mathrm{H}, \mathrm{CH}_{3} \mathrm{C}\right) ;{ }^{13} \mathrm{C} \mathrm{NMR}$ $\left(\mathrm{CDCl}_{3}\right) \delta / \mathrm{ppm}: 161.31$ (s, C-4'), 149.48 (s, C-2'), 148.85 (d, C-6'), 113.03 (s, O-C-O), 110.93 (d, C-1), 98.61 (s, C-5'), 84.98 (d, C-3), 83.95 (d, C-4), 81.92 (s, $\underline{\mathrm{C}} \equiv \mathrm{CH}), 81.70(\mathrm{~d}, \mathrm{C}-2), 74.25(\mathrm{~d}, \mathrm{C} \equiv \underline{\mathrm{CH}}), 56.20 \quad(\mathrm{q}$, $\left.\mathrm{CH}_{3} \mathrm{O}\right), 51.85$ (t, C-5), 26.38 (q, $\left.\mathrm{CH}_{3} \mathrm{C}\right), 24.87$ (q, $\mathrm{CH}_{3} \mathrm{C}$ ). Anal. Calcd. mass fractions of elements, $w / \%$, for $\mathrm{C}_{15} \mathrm{H}_{18} \mathrm{~N}_{2} \mathrm{O}_{6}\left(M_{\mathrm{r}}=322.31\right)$ are: $\mathrm{C} 55.89, \mathrm{H} 5.63, \mathrm{~N}$ 8.69; found: C 55.68, H 5.73, N 8.62.

\section{Cell culturing and MTT test ${ }^{28,29}$}

Reversed nucleoside derivatives $\mathbf{1 2 - 1 5}$ and $\mathbf{1 7}$, in a parallel with 5-fluorouracil $\mathbf{5}$ as a standard antitumor drug, were selected for preliminary in vitro testing on cytotoxicity using 6 different human tumor cell lines: cervix adenocarcinoma (HeLa), pancreatic carcinoma (MIAPaCa2), laryngeal carcinoma (Hep-2), human caucasian bronchioalveolar carcinoma (NCI-H358), and colon carcinoma (HT-29, $\mathrm{CaCo} 2$ ). The cells were grown in monolayer at $37{ }^{\circ} \mathrm{C}$ in a humidified atmosphere with $5 \% \mathrm{CO}_{2}$ in Dulbecco's modified Eagle's medium (DMEM) supplemented with $10 \%(v / v)$ fetal bovine serum, $2 \mathrm{mM}$ glutamine, $100 \mathrm{U}$ penicillin and 100 $\mathrm{mg} / \mathrm{mL}$ streptomycin. Cell lines were incubated with four 10 -fold dilutions $\left(10^{-4}\right.$ to $\left.10^{-7} \mathrm{M}\right)$. After 72 hours of incubation the cell growth rate was evaluated using the MTT assay.

For the MTT test, cells were seeded on 96 micro well flat bottom plates (Greiner, Austria) at $2 \times 10^{4}$ cells $/ \mathrm{mL}$. After 72 hours of incubation with the tested compounds MTT (Merck, Germany) was added. DMSO (Merck, Germany) was used to dissolve the formed MTT-formazane crystals. Absorbency was measured at $570 \mathrm{~nm}$ on Stat fax 2100 plate reader (Awareness Technology Inc. USA). All experiments were performed three times in triplicates. The percentage of treated tumor cells growth inhibition was calculated relative to the growth of untreated (control) cells.

\section{RESULTS AND DISCUSSION}

The synthetic approach to reversed nucleoside analogues is based on the preparation of the already known, suitably protected methyl ribofuranoside $2(73 \%)$ and its transformation into 5-tosyl derivative 3 (76\%) by adopting the methods described in the literature (Scheme 1). ${ }^{23,24}$ Following our previously described approach to reversed nucleosides, the sodium salts of the uracil derivatives 4-6 were reacted with ribofuranoside $\mathbf{3}$ giving the corresponding reversed nucleosides 7, 8 and $\mathbf{1 0}$ (Scheme 1). ${ }^{19,21}$

It was reported that the condensation of thymine sodium salt with the tosyl monosaccharide $\mathbf{3}$ gave two regioisomers containing the ribofuranoside attached at $\mathrm{N} 1{ }^{\prime}$ or N3' position of the thymine ring. ${ }^{30}$ However, we were not able to identify formation of the $N-3^{\prime}$ regioisomer in the reaction of uracil derivatives 4-6 with 3 and, exclusively the corresponding $N-1^{\prime}$ regioisomers 7,8 and $\mathbf{1 0}$ were isolated. The structures of the reversed nucleosides $\mathbf{7 , 8}$ and $\mathbf{1 0}$ were confirmed by NMR, FTIR and elemental analyses. The formation of the $N-1^{\prime}$ - and not the $N$-3'-regioisomers of 7, 8 and $\mathbf{1 0}$ is apparent from their ${ }^{1} \mathrm{H}$ NMR spectra. In the spectrum of 7, the signal of $\mathrm{C}^{\prime}$ proton appears as a doublet of doublets due to the vicinal H5'-H6' coupling $\left(J_{5^{\prime}, 6^{\prime}}=7.9\right.$ $\mathrm{Hz})$ and the additional long-range H5'-NH3' coupling $\left(J_{5^{\prime}, \mathrm{NH}-3^{\prime}}=2.1 \mathrm{~Hz}\right)$, the latter excluding the $N$-3'-regional isomer structure. In addition, in the spectra of 7, 8 and 10 the NH proton signals appear at $\delta 9.38 ; 11.7$ and 11.87 ppm, respectively, being the characteristic chemical shifts of the uracil NH-3' protons.

5-Fluorouracil $\mathbf{5}$ is well known to exhibit a strong antitumor activity but its toxicity largely limits the use of 5 as a practical antitumor agent for humans. ${ }^{31} \mathrm{We}$ examined the possibility to prepare the reversed nucleoside 8 incorporating 5-fluorouracil fragment. The sodium salt of 5-fluorouracil $\mathbf{5}$ was condensed with tosyl ribofuranoside 3 giving the $N$-1'-regioisomer of reversed nucleoside 8 in $23 \%$ yield and also the novel $N-1^{\prime}, N-3^{\prime}-$ disubstituted nucleoside 9 in $25 \%$ yield. In the ${ }^{1} \mathrm{H}$ NMR spectra of both, 8 and 9 the signal of H-6' vinyl proton is split into a doublet (8: $\delta=8.08 \mathrm{ppm},{ }^{3} J_{\mathrm{H} 6 '-\mathrm{F}}=6.9 \mathrm{~Hz}$; 9: $\left.\delta=8.19 \mathrm{ppm},{ }^{3} J_{\mathrm{H} 6}-\mathrm{F}=6.5 \mathrm{~Hz}\right)$ due to the H-F coupling.

Since the yields of the reversed nucleosides 7 and 8 prepared from uracil 4 and 5-fluorouracil 5 sodium salts were relatively low, we examined the condensation of tosyl ribofuranoside $\mathbf{3}$ with the 5-iodouracil $\mathbf{6}$ which upon N1'-deprotonation should be better nucleophile compared to the corresponding anions of $\mathbf{4}$ and $\mathbf{5}$, due to electron donating effect of iodine. The $N$-1'-regioisomer 10 was obtained in $58 \%$ yield together with the very small amount of the novel $N-1^{\prime}, N-3^{\prime}$-disubstituted nucleoside derivative $11(1.5 \%)$. The hydrogenation of $\mathbf{1 0}$ 
<smiles>COC1OC(CO[As])C2OC(C)(C)OC12</smiles>

3<smiles>[R]c1c[nH]c(=O)[nH]c1=O</smiles>

$4 \mathrm{R}=\mathrm{H}$ $5 \mathrm{R}=\mathrm{F}$ $6 \mathrm{R}=\mathrm{I}$

H-6'

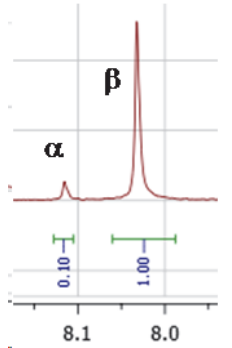

14

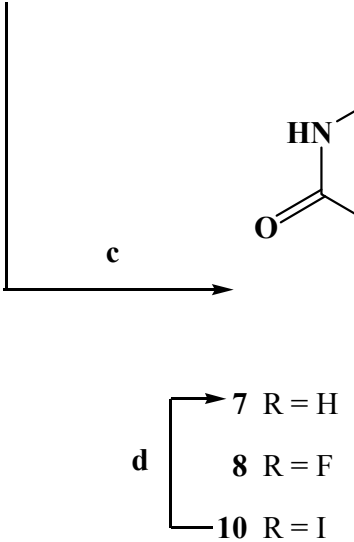

H-1

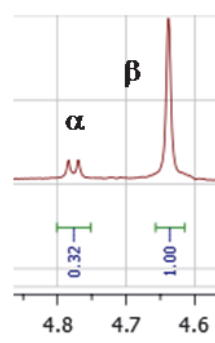

13<smiles>COC1OC(CO)C2OC(C)(C)OC12</smiles>

2<smiles>OCC1OC(O)C(O)C1O</smiles>

1<smiles>[R]OC1OC2OC3C(CN4C=C([R])C(=C)N(CC5OC(C)(C)OC5C4OC)C2=O)OC(OC3OC)C1O</smiles>

e

$11 \mathrm{R}=\mathrm{I}$

e<smiles>[X]c1cn(CC2OC(OC)C(O)C2O)c(=O)[nH]c1=O</smiles><smiles>COC1OC(Cn2cc(F)c(=O)n(CC3OC(OC)C(O)C3O)c2=O)C(O)C1O</smiles>

Scheme 1. (a) 1. $\mathrm{HCl} / \mathrm{MeOH}$, 2. 2,2-dimethoxypropane, acetone; (b) TsCl/Py; (c) NaH/DMF; (d) $\mathrm{H}_{2}, \mathrm{Pd} / \mathrm{C}, 0.1 \mathrm{M} \mathrm{NaOH}, \mathrm{MeOH}$; (e) Amberlite IR-120 $\left(\mathrm{H}^{+}\right), \mathrm{MeOH}$, reflux. The ratio of anomers $13(\alpha / \beta 3: 10)$ and $\mathbf{1 4}(\alpha / \beta 1: 10)$ as determined by ${ }^{1} \mathrm{H}$ NMR spectra (inset).

using $\mathrm{Pd} / \mathrm{C}$ catalyst afforded the reversed nucleoside 7 in $82 \%$ yield (Scheme 1). By the latter two step preparation, 7 could be prepared in higher yield than in the direct condensation of the sodium salt of uracil 4 with 3.

The ${ }^{1} \mathrm{H}$ NMR spectra of the isopropylidene protected reversed nucleosides $\mathbf{7 , \mathbf { 8 }}$ and $\mathbf{1 0}$ as well as those of the equally protected $N-1^{\prime}, N-3^{\prime}$-disubstituted nucleosides 9 and 11 conclusively show that all posses the $\beta$ configuration. In each spectrum, the anomeric $\mathrm{C} 1$ proton appears as the singlet due to small coupling constant with the proton at $\mathrm{C} 2$ ribose.

The isopropylidene protecting groups of 7-10 were removed by using of Amberlite IR-120 $\left(\mathrm{H}^{+}\right)$ion exchange resin in refluxing methanol to yield the corresponding methyl ribofuranoside reversed nucleosides (12-15) in 65-89\% yields (Scheme 1). The ${ }^{1} \mathrm{H}$
NMR spectrum of $\mathbf{1 4}$ reveal the presence of duplicate peaks for H-6' proton due to the presence of an anomeric mixture in the ratio $\alpha / \beta=1: 10$ and in the spectrum of 13 signals of protons at $\mathrm{C} 1$ position $(\alpha / \beta=$ $3: 10)$ are well separated as shown in the inset of Scheme 1.

The 5'-iodo reversed nucleoside $\mathbf{1 0}$ is suitable for further functionalization at the uracil ring. It is well known that the coupling of terminal alkynes with 5-iodouracil nucleosides proceeds in high yields in the presence of palladium catalyst. ${ }^{32}$ Treatment of 10 with ethynyltrimethylsilane and $\left(\mathrm{PPh}_{3}\right) \mathrm{PdCl}_{2}$ in the presence of $\mathrm{CuI}$ and triethylamine afforded $\mathbf{1 6}$ in $71 \%$ yield (Scheme 2). The structure of $\mathbf{1 6}$ was confirmed by the presence of acetylenic band in the IR spectrum $\left(v 2160 \mathrm{~cm}^{-1}\right)$ and further supported by the 
<smiles>CC1(C)OC2C(O)OC(Cn3cc(I)c(=O)[nH]c3=O)C2O1</smiles><smiles>C#CC(C)C</smiles><smiles>C#Cc1cn(CC2OC(OC)C3OC(C)(C)OC23)c(=O)[nH]c1=O</smiles>

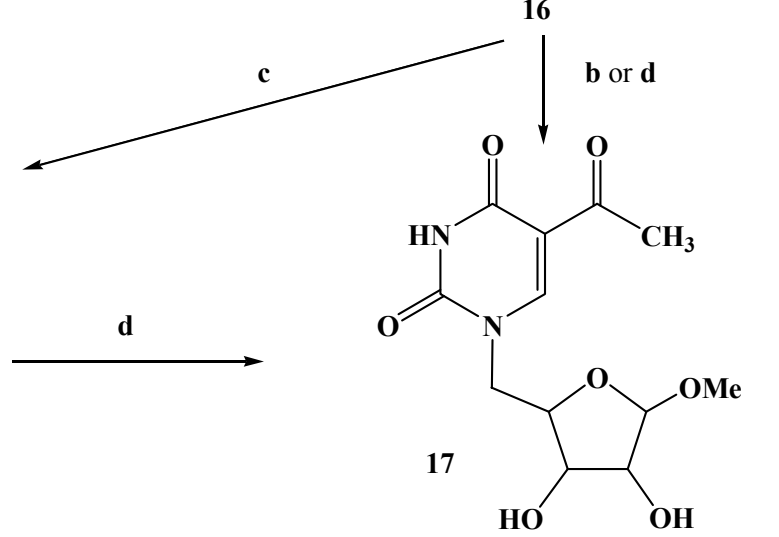

Scheme 2. (a) $\mathrm{PdCl}_{2}\left(\mathrm{PPh}_{3}\right)_{2}, \mathrm{CuI}, \mathrm{Et}_{3} \mathrm{~N}$; (b) Amberlite IR-120 (H+), MeOH, reflux; (c) NaOMe/MeOH, rt; (d) 50 \% TFA/H2O.

${ }^{1} \mathrm{H}$ NMR and elemental analysis (see Experimental part).

Using acidic ion exchange resin in methanol or 50 $\%$ aqueous TFA for isopropylidene and trimethylsilyl deprotection of $\mathbf{1 6}$ gave 5'-acetyl reversed nucleoside $\mathbf{1 7}$ in $78 \%$ yield. As it was described in the literature 5ethynyl-2'-deoxyuridine could be hydrated by dilute sulphuric acid to give 5-acetyl derivative in high yield. ${ }^{33,34}$ Hence, during deprotection of 16, under acidic conditions besides removal of isopropylidene and trimethylsilyl groups the addition of water on the acetylenic bond occurred giving the 5'-acetyl derivative 17. Treatment of 16 with $0.2 \mathrm{M}$ sodium methoxide in dry methanol effected removal of the trimethylsilyl group giving 5'-ethynyl reversed nucleoside $\mathbf{1 8}$ in $88 \%$ yield. The removal of isopropylidene group of $\mathbf{1 8}$ by $50 \%$ aqueous TFA gave the 5'-acetyl $\mathbf{1 7}$ in almost quantitative yield (Scheme 2).

The reversed nucleosides $\mathbf{1 2 - 1 5}$ and $\mathbf{1 7}$ were evaluated for their antitumor activity in vitro against HeLa, MIAPaCa2, Hep2, NCI-H358, CaCo-2, and HT29 cell lines using 3-(4,5-dimethylthiazol-2-yl)-2,5diphenyl-2H-tetrazoliumbromide (MTT) assay method. ${ }^{28,29}$ The reference drug used was 5-fluorouracil. The activity of the samples and the reference drug was assayed under identical conditions at concentrations of $10^{-4} \mathrm{M}$ to $10^{-7} \mathrm{M}$.
Among the tested compounds only 5'-iodo reversed nucleoside 14 (Figure 1) showed a moderate cytostatic activity against $\mathrm{CaCo}-2$ cell line (50\% growth inhibition $\mathrm{c}=10^{-4} \mathrm{M}$ and $30 \%$ growth inhibition $\left.\mathrm{c}=10^{-6}-10^{-7} \mathrm{M}\right)$, which indicates that further synthetic variations of $\mathbf{1 4}$ may result in the preparation of derivatives with improved cytostatic potential.

\section{CONCLUSIONS}

In this work we describe the synthetic approach to reversed nucleosides which enables their preparation in gram quantities. The reaction of the sodium salt of various pyrimidine nucleobases $4-6$ with a suitably protected ribofuranoside $\mathbf{3}$, enable the efficient preparation of the reversed pyrimidine nucleosides $(\mathbf{7}, \mathbf{8 , 1 0})$. In some cases also $N$-1, $N$-3-diribofuranosyl substituted nucleosides 9 and 11 were isolated. The 5'-iodo reversed nucleoside $\mathbf{1 0}$ was suitable for further functionalization at the uracil and by using the Sonogashira coupling 5'ethynyl reversed nucleoside $\mathbf{1 6}$ was synthesized and transformed to 5'-acetyl derivative $\mathbf{1 7}$ under acidic conditions. The reversed nucleosides $\mathbf{1 2 - 1 5}$ and $\mathbf{1 7}$ were tested for the antiproliferative activity on the panel of six cell lines (HeLa, MIAPaCa2, Hep2, NCI-H358, CaCo-2, and HT-29). Modest growth inhibition was 


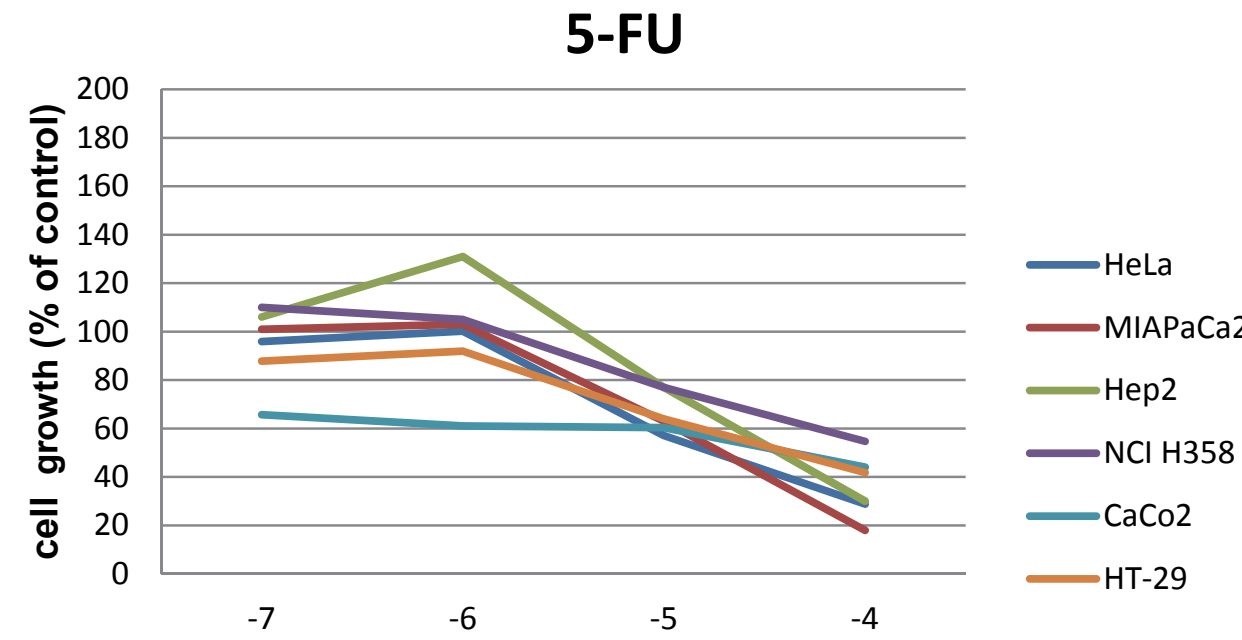

$\log 10$ concentration (M)

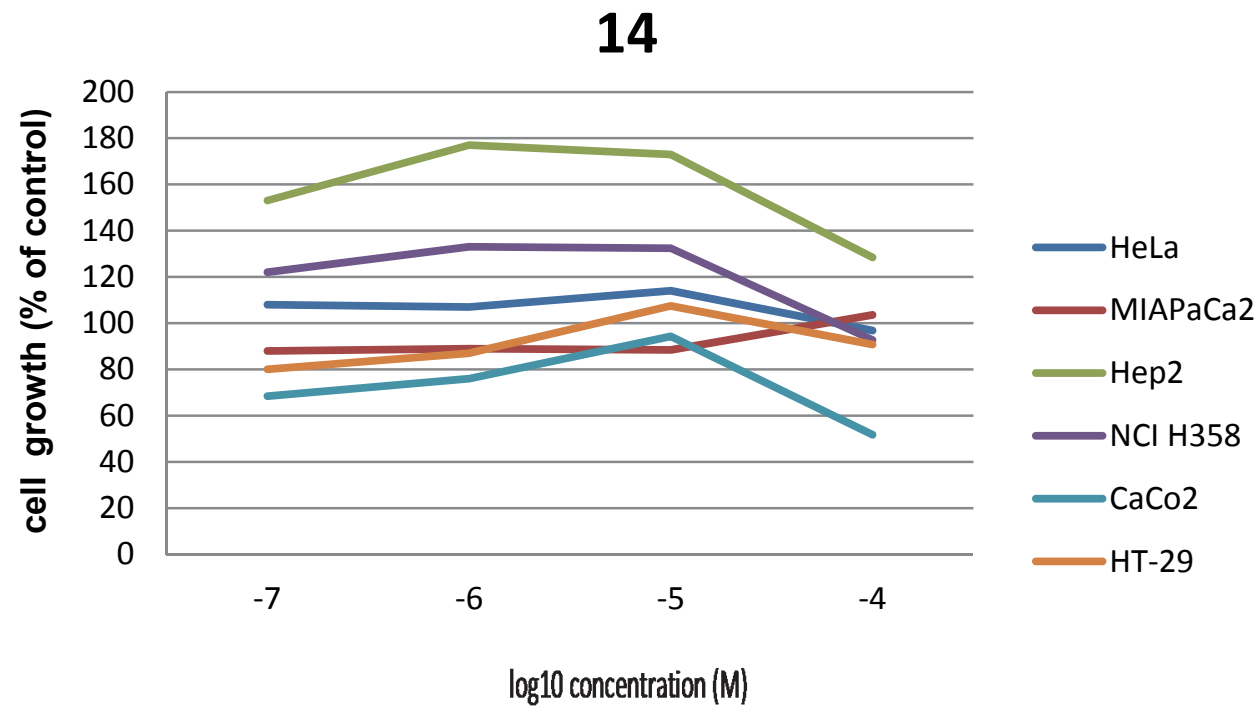

Figure 1. Cytotoxic effects of 5-fluorouracil 5 (5-FU) and 5'-iodo reversed nucleoside $\mathbf{1 4}$ on the growth of tumor cell lines after $72 \mathrm{~h}$ of incubation in the final concentration range $\left(10^{-4}-10^{-7} \mathrm{M}\right)$. Cytotoxicity was analyzed using the MTT survival assay.

obtained only for compound $\mathbf{1 4}$ and the CaCo-2 cell line at the highest concentration regime $(50 \%$ growth inhibition $\left.c=10^{-4} \mathrm{M}\right)$.

Acknowledgements. This work was supported by the Ministry of Science, Education and Sports of the Republic of Croatia through Grant No. 098-0982914-2935.

\section{REFERENCES}

1. E. De Clercq, Annu. Rev. Pharmacol. Toxicol. 51 (2011) 1-24.

2. C. D. Meadows and J. Gervay-Hague, Chem. Med. Chem. 1 (2006) 16-29.

3. C. Mathé and G. L Gosselin, Antiviral Res. 71 (2006) 276-281.

4. D. Komiotis, S. Manta, E. Tsoukala, and N. Tzioumaki, Curr.
Med. Chem.: Anti-Infect. Agents 7 (2008) 219-244.

5. C. M. Galmarini, J. R. Mackey, and C. Dumontet, Lancet Oncol. 3 (2002) 415-424.

6. D. Sampath, V. A. Rao, and W. Plunkett, Oncogene 22 (2003) 9063-9074.

7. P. Herdewijn (Ed.), Modified Nucleosides: in Biochemistry, Biotechnology and Medicine, John Wiley \& Sons, 2008.

8. P. Merino (Ed.), Chemical Synthesis of Nucleoside Analogues, John Wiley \& Sons, 2013.

9. J. W. Beach, L. S. Jeong, A. J. Alves, D. Pohl, H. O. Kim, C.-N. Chang, S.-L. Doong, R. F. Schinazi, Y.-C. Cheng, and C. K. Chu, J. Org. Chem. 57 (1992) 2217-2219.

10. V. Nair, M. St. Clair, J. E. Reardon, H. C. Krasny, R. J. Hazen, M. T. Paff, L. R. Boone, M. Tisdale, I. Najera, R. E. Dornsife, D. R. Everett, K. Borroto-Esoda, J. L. Yale, T. P. Zimmerman, and J. L. Rideout, Antimicrob. Agents Chemother. 39 (1995) 1993-1999. 
11. I. Verheggen, A. Van Aerschot, L. Van Meervelt, J. Rozenski, L. Wiebe, R. Snoeck, G. Andrei, J. Balzarini, P. Claes, E. De Clercq, and P. Herdewijn, J. Med. Chem. 38 (1995) $826-835$.

12. J.-F. Wang, X.-D. Yang, L.-R. Zhang, Z.-J. Yang, and L.-H. Zhang, Tetrahedron 60 (2004) 8535-8546.

13. T. Bouisset, G. Gosselin, L. Griffe, J.-C.Meillon, and R. Storer, Tetrahedron 64 (2008) 6657-6661.

14. M. Kawazu, T. Kanno, S. Yamamura, T. Mizaguchi, and S. Saito, J. Org. Chem. 38 (1973) 2887-2890.

15. A. Holý, Collect. Czech. Chem. Commun. 40 (1975) 187-214.

16. S. N. Mikhailov, L. I. Kolobushkina, A. M. Kritzyn, and V. L. Florentiev, Tetrahedron 32 (1976) 2409-2415.

17. A. Holý, Collect. Czech. Chem. Commun. 49 (1984) 2148-2166.

18. V. Škarić and B. Kašnar Croat. Chem. Acta 58 (1985) 583-592.

19. B. Kašnar, V. Škarić, B. Klaić, and M. Žinić, Tetrahedron Lett. 34 (1993) 4997-5000.

20. N. F. Zakirova, A. V. Shipitsyn, E. F. Belanov, and M. V. Jasko, Bioorg. Med. Chem. Lett. 14 (2004) 3357-3360.

21. B. Kašnar, Nucleosides \& Nucleotides 14 (1995) 341-344.

22. Unpublished results in: N. Župančić, PhD Thesis, 2014.

23. N. J. Leonard and K. L. Carraway, J. Heterocyclic Chem. 3 (1996) 485-489.
24. Adel A.-H. Abdel-Rahman, Ahmed E.-S. Abdel-Megied, Adel E.-S. Goda, Ibrahim F. Zeid, and El Sayed H. El Ashry, Nucleosides Nucleotides \& Nucleic Acids 22 (2003) 2027-2038.

25. T. B. Johnson and C. O. Johns, J. Biol. Chem. 1 (1906) 305-318.

26. J.-I. Asakura and M. J. Robins, J. Org. Chem. 55 (1990) 4928-4933.

27. Z. Janeba, J. Balzarini, G. Andrei, R. Snoeck, E. De Clercq, and M. J. Robins, Can. J. Chem. 84 (2006) 580-586.

28. N. Horiuchi, K. Nagawa, Y. Sasaky, K. Minato, Y. Fujiwara, K. Nezu, Y. Ohe, and N. Sajo, Cancer Chemother. Pharmacol. 22 (1988) 246-250.

29. G. Mickisch, S. Fajta, H. Bier, R. Tschada, and P. Alken, Urol. Res. 19 (1991) 99-103.

30. A. Holy, Collect. Czech. Chem. Commun. 40 (1975) 187-214.

31. J. L. Yamashita, I. Yamawaki, S. Ueda, M. Yasumoto, N. Unemi, and S. Hashimoto, Chem. Pharm. Bull. 30 (1982) 4258-4267.

32. K. Sonogashira, Y. Tohda, and N. Hagihara, Tetrahedron Lett. 16 (1975) 4467-4470.

33. P. J. Barr, P. Chananont, T. A. Hamor, A. S. Jones, M. K O'leary, and R. T. Walker, Tetrahedron 36 (1980) 1269-1273.

34. F. Amblard, V. Aucagne, P. Guenot, R. F. Schinazic, and L. A. Agrofoglioa, Bioorg. Med. Chem. 13 (2005) 1239-1248. 